\title{
Barrier free environment: a case study to evaluate Misr railway station for accessibility
}

\author{
H. El Naggar ${ }^{1}$, G. Mossad ${ }^{2,3}$ \& K. Tarabieh ${ }^{2,3}$ \\ ${ }^{1}$ The Arab Academy for Science and Technology and Maritime Studies, \\ Egypt \\ ${ }^{2}$ Architecture and Interior Design Department, \\ The Arab Academy for Science and Technology and Maritime Studies \\ (AASTMT), Egypt \\ ${ }^{3}$ Sustainable Design Department, The American University in Cairo \\ (AUC), Egypt
}

\begin{abstract}
Egypt is undergoing a series of rapid changes at social, economic and environmental levels as a result of the implementation of a new legislation and constitutional amendments that promise to guarantee the rights of citizens to live in a safe environment. As a result, one of the main population sectors affected are the elderly and people with disabilities. As Egypt undergoes a series of reforms on many levels, expected changes in the current legislation governing physical planning and urban design approached will soon take effect. Among these changes is the creation of a barrier free environment incorporating social and economic dimensions. The aim of the paper is to present the challenges facing people with disabilities in the city of Alexandria focusing on mass transit stations, to evaluate the current design standards and policies, to analyze best practices around the world in similar cities and suggests a better means of integration with the society. The paper method utilized quantitative and qualitative approaches and was applied accordingly to achieve the objectives of the study. A number of similar case studies were analyzed in depth and lists of applicable design criteria were generated. The quantitative analysis includes measurement and evaluation of the adherence of such popular locations to internationally known universal design checklist, while the qualitative tools justified and interpreted the collected data with the support of structured interviews and policy analysis. The paper evaluates the main train station in the city "Misr railway station" as a case study which is located in the center of the city and documents the accessibility of the station in its current condition and the applicability of new solutions. The paper concludes with conclusions and recommendations that should be
\end{abstract}


implemented in the current policies governing the city and for use by architects and urban designers in the future.

Keywords: barrier free, universal design, persons with disabilities, transportation, Egypt.

\section{Introduction}

The barrier free environment issue is an emergent objective for the current situation for Egypt and its urban planning, which is a must due to the lack awareness and understanding for its concept and process in our societies, governments, the private sector, and donor communities. In addition to, the percentage of the disabled according to the literature of public mobilization and statistics 2006 was about 8 millions which is about $10 \%$ of the Egyptian population, moreover, that the percentage is not including the old people and young ones who are always in need for help and flexible design. By implement Universal Design as a strategy to ensure equal rights in society for all individuals, regardless of age, abilities or cultural background, including persons with disabilities will be more humanitarian.

\section{Environmental interventions for people with physical limitation and elderly population in Egypt}

The governmental compliance with UN standard rules was assessed by the Egyptians government and the World Federation of the Association of the Deaf "WFD-Egypt", which is a national affiliate of the international organization of the WFD [1].

a) General polices:

The policy stresses on rehabilitation, individual support, prevention, antidiscrimination law as well as accessibility measures.

b) Legislation:

The rights of persons with disabilities are protected by both general and special legislation. However the WFD reported that these are only protected by special legislation.

According to the government the general legislation applies to persons with disabilities education, employment and right to marriage. The law also guarantees the benefit of independent living to persons with disabilities.

c) Accessibility:

The WFD reported that there are rules to ensure accessibility of the built environment, but they aren't working since 2006 till now, besides, there are no special transport arrangements for persons with disabilities.

\section{Mass transportation for persons with disabilities in Egypt}

Transportation is considered as unpleasant for all disabled since that no transportation mean is accessible or having the services to allow all users to use 
it. The wheel chair users shared their views that the inaccessibility of the transport system and the built environment is very inconvenient. Most of users are expected that the public transportation like railway station should be accessible from the entrance to the train vehicles. As a result for the problems facing the persons with disabilities it's a must to create a barrier free environment and using the universal design compliance for mass transportation.

\section{Universal design in mass transportation}

Universal design allows people with disabilities to participate fully in society, by improving mobility options it tends to increase public health and it gives people with physical disabilities better mobility and accessibility opportunities.

a) Terminal design:

The goal is to ensure that information or services delivered through a public access terminal are available to and usable by the widest possible audience. This requires that the following five conditions are met:

- All users can reach and operate the controls, inputs and outputs.

- All users can perceive and understand the operation of controls, inputs and outputs.

- For users who cannot use the terminal, an equivalent alternative service is available [2]

b) Information resources:

The United Nations have a useful set of anthropometrical data covering ranges of height and reach when standing or sitting in a wheelchair, plus required path and turning space dimensions for wheelchairs.

- $\quad$ Ensure that all operable parts are reachable by people of all heights and people sitting in a wheelchair or buggy (as shown in figure 1).
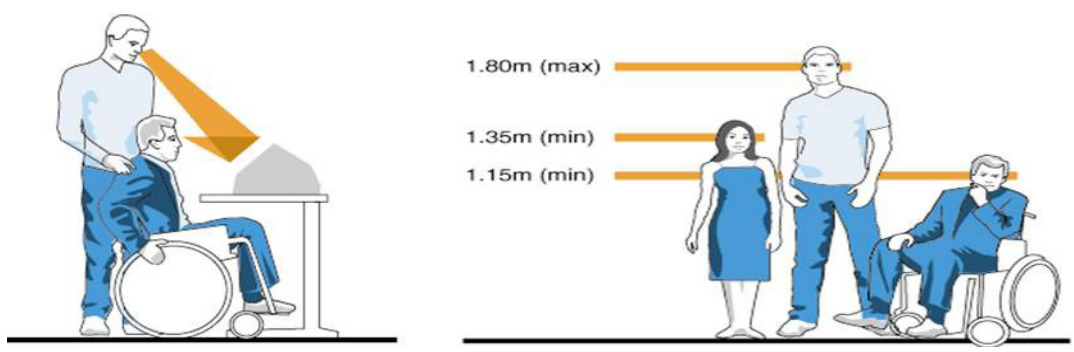

Figure 1: $\quad$ Common reach zones [2].

- Ensure that displays are within sight of people of all heights and people sitting in a wheelchair or buggy.

- Ensure that users with restricted or no vision can use all functions of the terminal. 
- $\quad$ Use the simplest language possible for instructions, prompts and outputs and, where possible, supplement it with pictorial information or spoken language.

- Ensure that an equivalent service is available through an accessible channel for users who cannot use the terminal [2].

c) Loading vehicles:

One of the most difficult issues in universal design of transportation systems is accommodating level changes to board and exit vehicles.

As recommendations for Design of Vehicle Loading Areas that can fit any place:

- Eliminate the change in level between vehicle floor and loading surface wherever possible.

- Provide mechanical loading systems when level changes cannot be eliminated.

- $\quad$ Eliminate the gap between platform and vehicle either by initial design or through mechanical means when a vehicle stops.

- Warn passengers on the platform of arriving vehicles, using both visual and audible mean [3].

d) Vehicles design:

Wheelchairs are often wider than the aisles in buses, trains, and airplanes; and if not positioned out of the way, they can create an impassible aisle for other passengers.

The recommendations for Vehicle Design are the following:

- Provide space for wheelchair users in the vehicle with safe secure systems.

- $\quad$ Develop universal secure devices that can be used independently.

- $\quad$ Provide priority seating for people who have difficulty standing.

- Include accessible toilet compartments on long-distance transport [3].

As the universal design international guidelines was published a lot of countries had applied it in their mass transportation to reach the highest quality of life by creating their own code or by applying the international guidelines to its mass transportation, Egypt was one of those countries which create its own code based on the international guidelines and principles but the latest Egyptian code for design urban open spaces and buildings for disabled (2003) didn't put the railway stations designs and needs in its consideration. On the Other hand, some countries did both ways to create their own code and use it in its mass transportation; two of those countries are Toronto, Canada and Dubai, United Arab of Emirates. In the following table 1 there is a comparison between the two examples to find out how the principles have been applied in both examples.

The two previous examples show how to capitalize on universal design principals which portrays the following focal conclusions. In "Train station module - Queen Street west, Toronto, Canada": This module has been established since 1885 with multiple barriers to the disabled; in 1998 this module was upgraded to accommodate the universal design principals allowing all people disabled to use public transportation. This example is considered as one of the most successful modules which accommodate a multiple techniques to 
Table 1: $\quad$ Comparison of examples $[4,5]$.

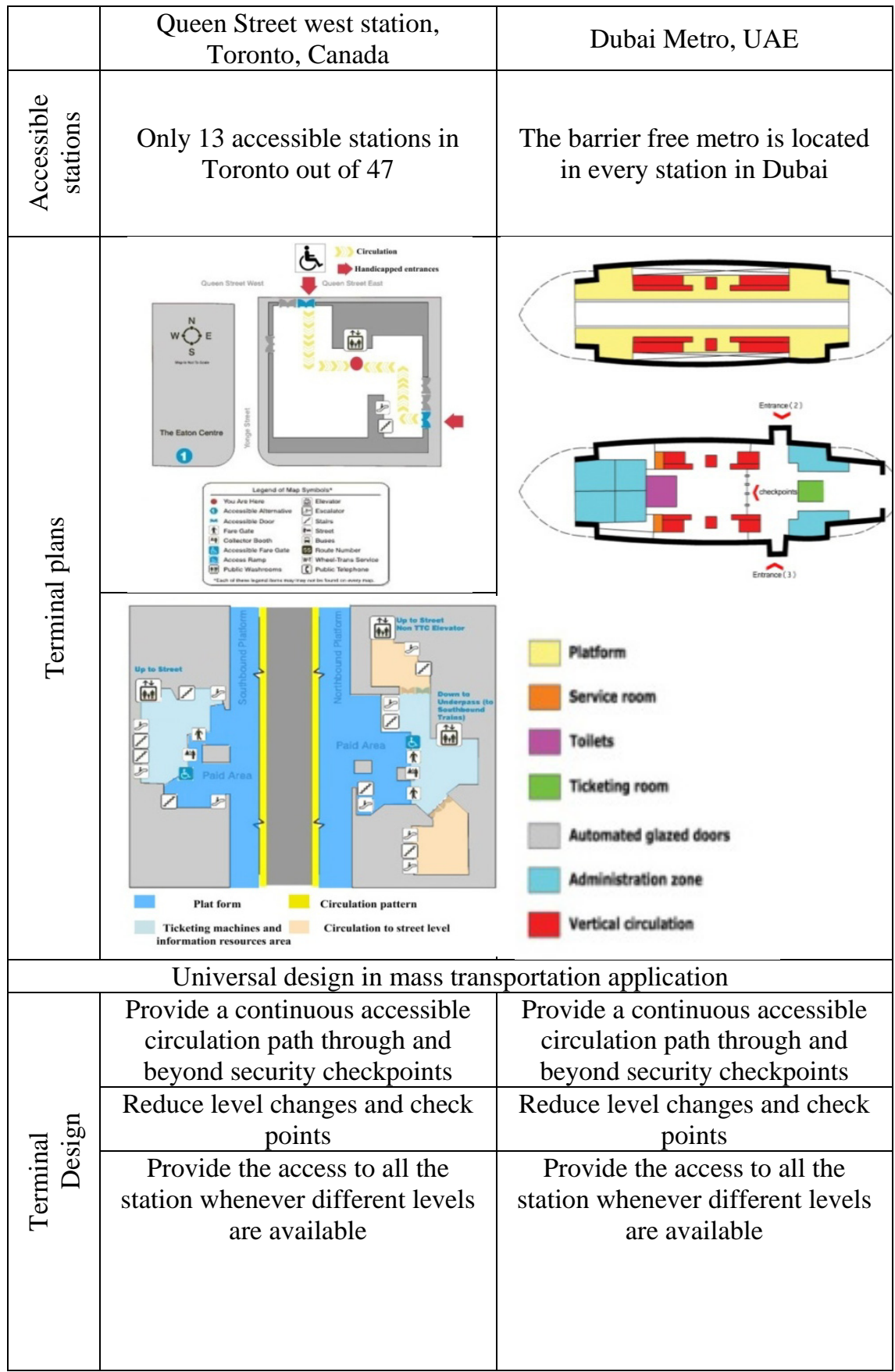


Table 1: $\quad$ Continued.

\begin{tabular}{|c|c|c|}
\hline & \begin{tabular}{|c|} 
Queen Street west station, \\
Toronto, Canada
\end{tabular} & Dubai Metro, UAE \\
\hline \multirow{4}{*}{ 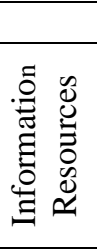 } & Ticketing machines are provided & Ticketing machines are provided \\
\hline & $\begin{array}{c}\text { Simplest language are used for } \\
\text { all instructions }\end{array}$ & $\begin{array}{l}\text { Simplest language are used for } \\
\text { all instructions }\end{array}$ \\
\hline & Ticketing machines are provided & Ticketing machines are provided \\
\hline & $\begin{array}{l}\text { Provide ramps needed directly in } \\
\text { front of the terminal. }\end{array}$ & $\begin{array}{l}\text { No ramps are Provided in front } \\
\text { of the terminal. }\end{array}$ \\
\hline \multirow{4}{*}{ 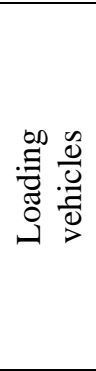 } & $\begin{array}{l}\text { A big gap between the platform } \\
\text { and the vehicle }\end{array}$ & $\begin{array}{l}\text { The gap between the platform } \\
\text { and the vehicle is narrow }\end{array}$ \\
\hline & $\begin{array}{c}\text { No mechanical loading system } \\
\text { when level changes }\end{array}$ & $\begin{array}{l}\text { The vehicles and loading area are } \\
\text { same level }\end{array}$ \\
\hline & $\begin{array}{c}\text { Provide different pattern in front } \\
\text { of the vehicles }\end{array}$ & $\begin{array}{c}\text { Provide different pattern in front } \\
\text { of the vehicles }\end{array}$ \\
\hline & $\begin{array}{c}\text { No glazed automated sliding } \\
\text { doors }\end{array}$ & $\begin{array}{c}\text { Glazed enclosures with } \\
\text { automated sliding doors are } \\
\text { provided }\end{array}$ \\
\hline \multirow[t]{2}{*}{ 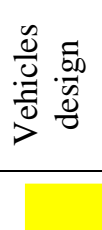 } & $\begin{array}{c}\text { Seats and floors are flat and } \\
\text { Clear signage is identify priority } \\
\text { seats }\end{array}$ & $\begin{array}{c}\text { Seats and floors are flat and } \\
\text { Clear signage is identify priority } \\
\text { seats }\end{array}$ \\
\hline & Not ac & Achieved \\
\hline
\end{tabular}

activate the theoretical principals into operation while "Metro station moduleDubai, UAE": This module was established in 2011targeting high standards of life thus, the government decided to apply accordingly the universal design principals as a part of the design consideration. This example is considered as the most updated version of techniques to activate the theoretical principals into actions matches the government vision.

\section{Evaluation of "Misr rail way station" for accessibility}

Alexandria is listed as the $2^{\text {nd }}$ largest country, second-largest city of Egypt, with a population of 4 million with high disabilities percentage (about 10\% of the total population of Alexandria), it consists of seven districts (Montaza, Sharak, Wasat, Goumrok, Gharb, Al Amrya and Borg El Arab) Misr railway station is located in El Attaren area in Wasat district (as shown in figure 2) [6].

In 1858 a railway station was built at existing central place which is very near to Misr station but in 1915 a competition began for the design of the new station instead of the old one, and it was completed at 1927. Now it is considered a land mark, high traffic area with various types of people. 


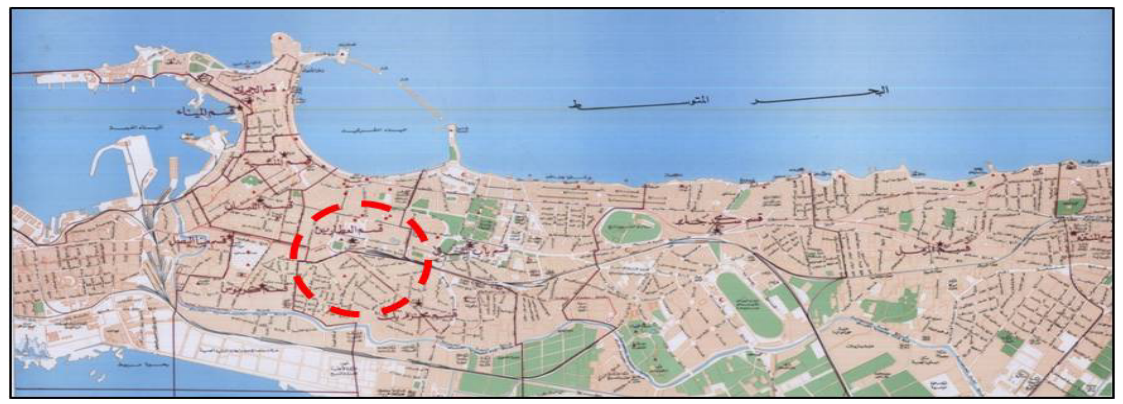

Figure 2: $\quad$ Alexandria districts and Misr railway station location.

Misr railway station is considered the most important railway station in Alexandria, the total area of the station is $3400 \mathrm{~m}^{2}$ including the outdoor area, it consists of four railway lines, the stations have two employees entrances while there are two entrances, one for passengers entrance and the other for exits (as shown in figure 3).

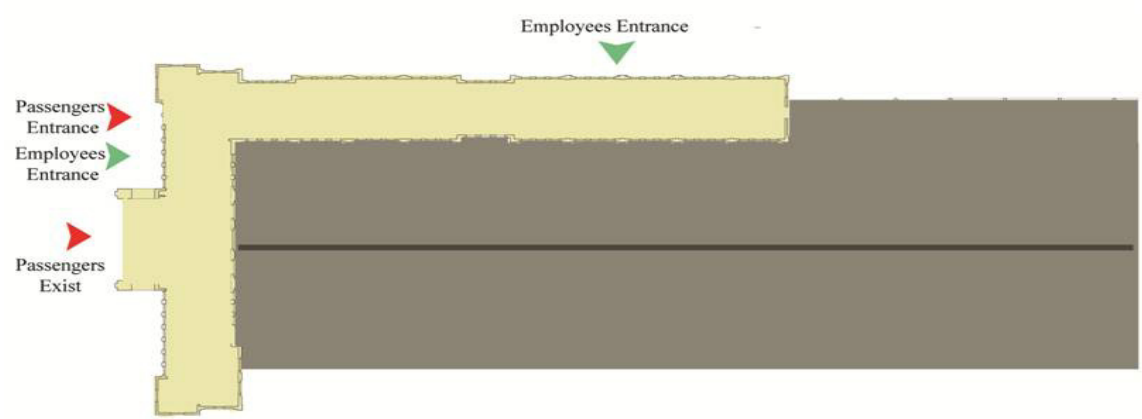

Figure 3: $\quad$ Misr railway station entrances and exits [6].

The station consist of two floors, the first floor consists of a Mosque, VIP waiting area, sleeping train waiting area, police station, pharmacy, toilets, ticketing offices, telephone and post office, maintenance room and sleeping train food storage while the second floor is mainly for administration zone it contains offices, storage, archive, station manager room, kitchenette and toilets as shown in figures 4 and 5 .

\subsection{The station's current situation:}

As a result, the headline priority to improve the existing situation is to create a barrier free environment in Alexandria; the following situation evaluation should be considered [6]. 


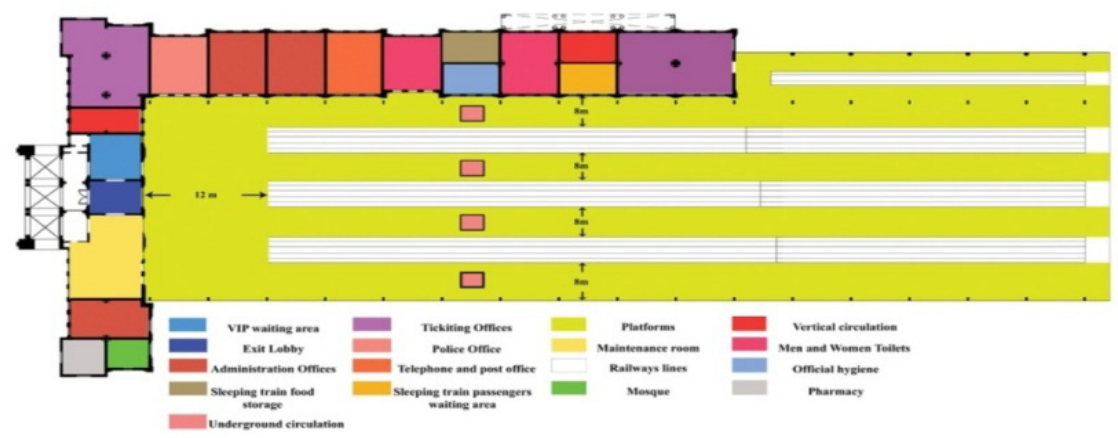

Figure 4: Zoning of the station's ground floor [6].

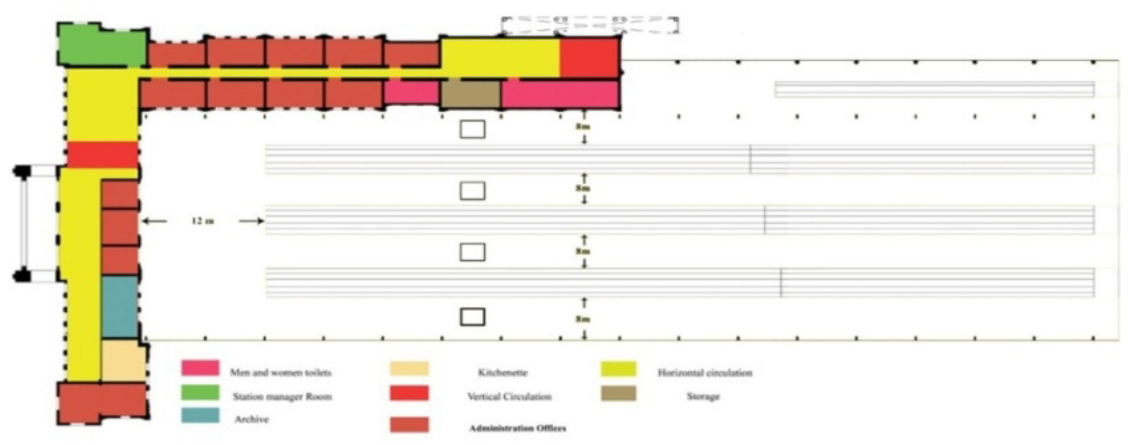

Figure 5: Zoning of the station's first floor [6].

\subsubsection{Terminal design}

The Misr railway station is considered as public terminal include Information kiosks, ticketing offices and Information displays. Also the information kiosks and the ticketing offices are maintaining a continuous accessible circulation path in front of them only, but not accessible to deal with them.

The station consists of two floors; the first floor is not accessible for the people with mobility impairment that because there is no elevator to help the people with functional limitations [6].

\subsubsection{Information resources}

All operable parts are not reachable by people of all heights and people sitting in a wheelchair or buggy, it is not refer to appropriate physical design guidelines or building accessibility guidelines which give minimum and maximum heights and reach distance [6]. 


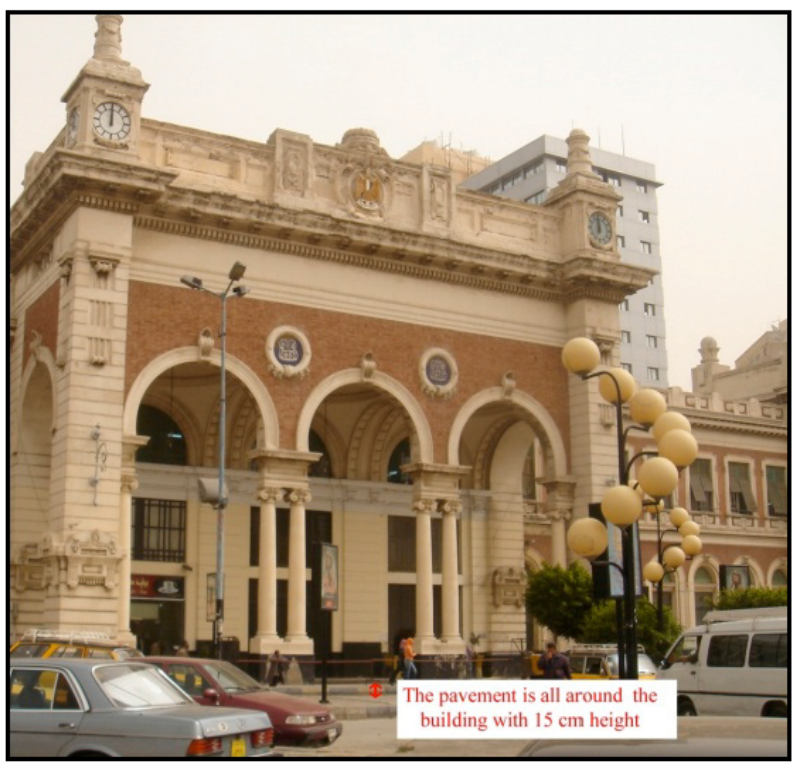

Figure 6: The obstacles facing users at the terminal entrance [6].

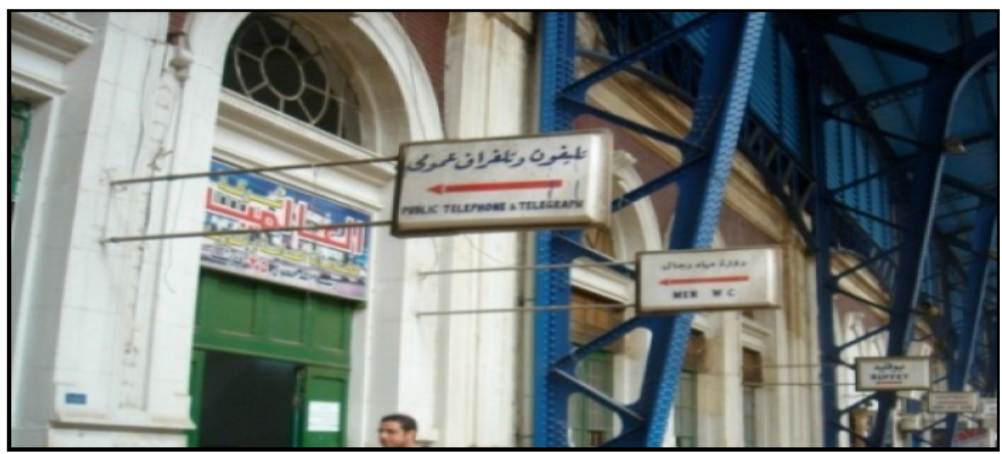

Figure 7: $\quad$ The signs and information resources in Misr railway station [6].

All the signs and the instructions use the simplest language possible (Arabic and English) but in a small font. Control labels, prompts and delivered information aren't usually provided as text but presented visually [6].

\subsubsection{Loading vehicles}

The platform is wide enough to contain the huge number of passengers used the terminal; flooring made of the same material, Also the gap between the platform and the vehicle is too big which isn't safe for wheelchairs and walking aids from getting caught in the gap. There is no secure system for protecting waiting 
passengers at the platform edge and even no glazed enclosures with automated sliding doors are introduced [6].

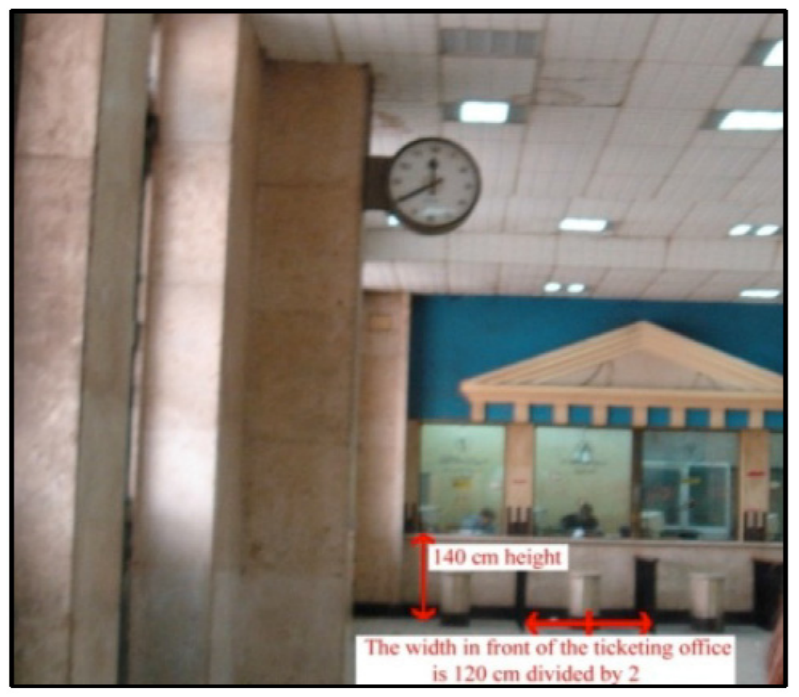

Figure 8: $\quad$ The ticketing space [6].

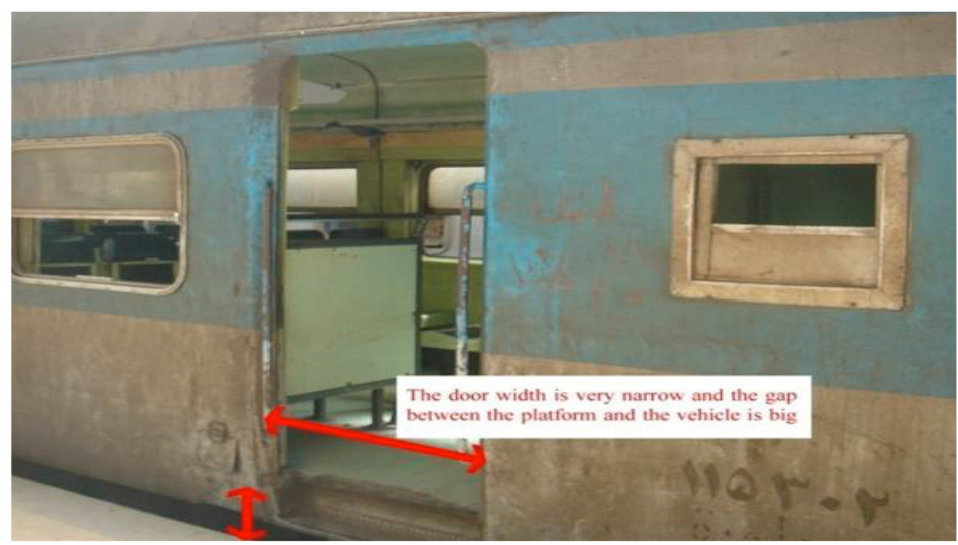

Figure 9: The gap between the vehicles and the platform [6].

\subsubsection{Vehicles' design}

The vehicles cannot contain people with functional disability; the corridors between the seats are very narrow which not allow a wheelchair to path through it.

There are no priority seats which are especially important in overcrowded vehicles. Clear signage should identify priority seats. And there are no removable 
seats to provide a designated wheelchair area and the use of folding seats is two other solutions [6].

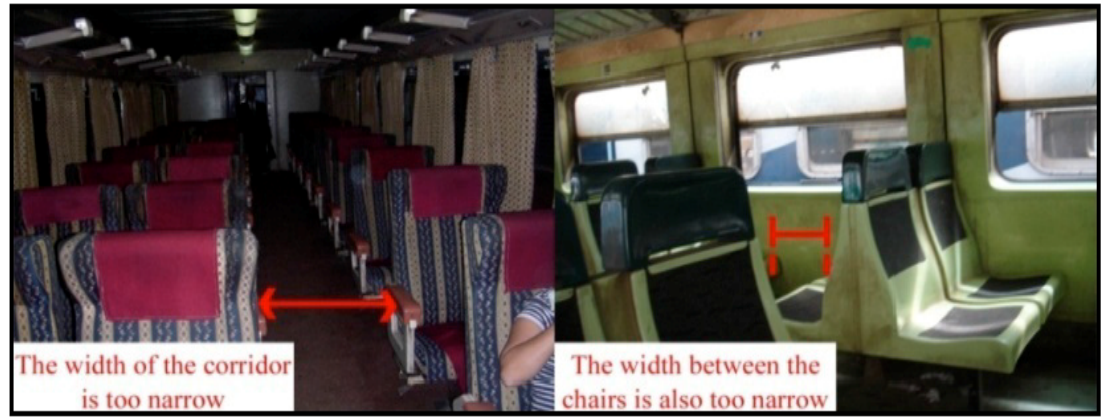

Figure 10: Design of the vehicles' seats [6].

\subsection{The station evaluation according the checklist}

Table 2: $\quad$ Evaluating the current situation of the transportation.

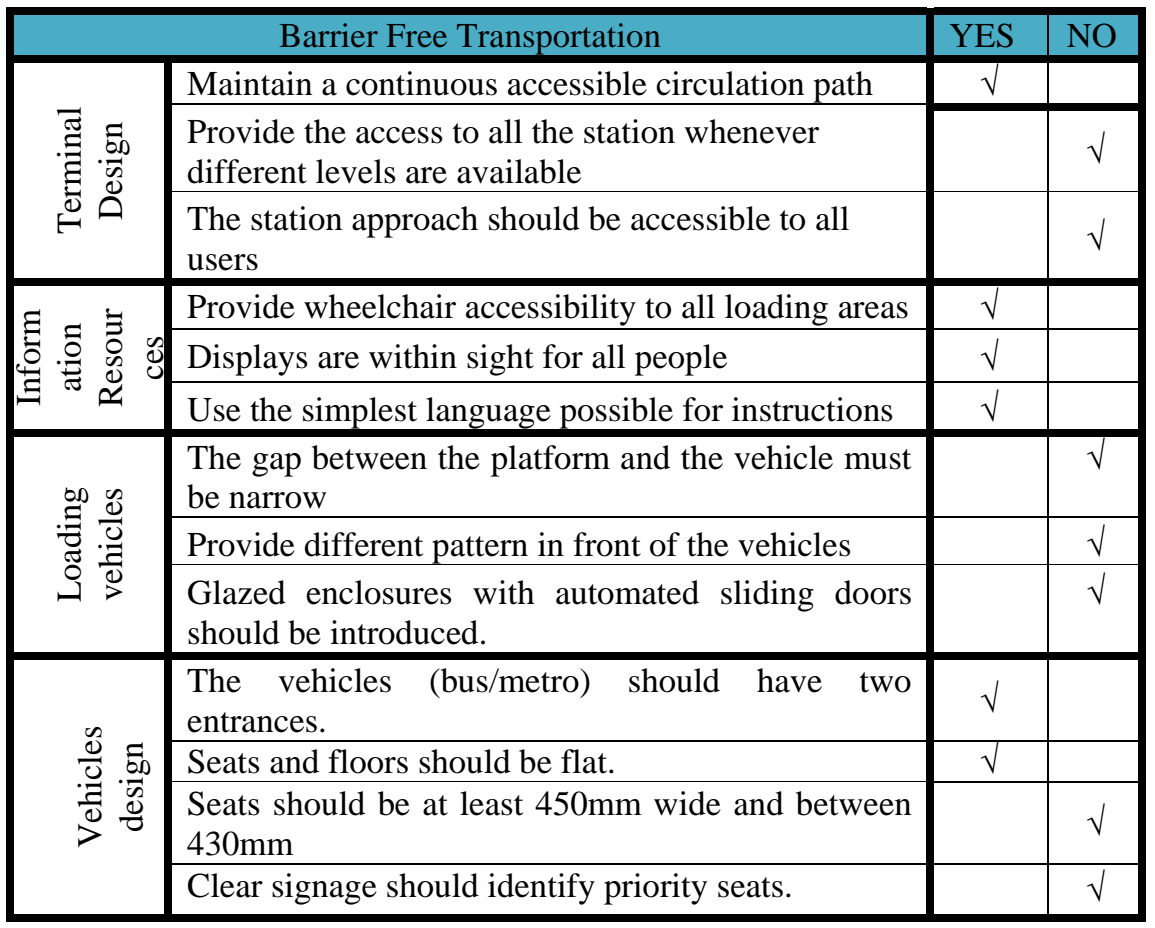




\section{Conclusion and recommendation}

The wheel chair users in the above case study shared their views that the inaccessibility of the transport system and the built environment is very inconvenient. Most of users are expected that the public transportation like railway station should be accessible from the entrance to the train vehicles.

General, The accessibility of the physical environment is a basic step to include people with disabilities as a part of the built environment .A minor step is a big problem for the independent access of elderly and physically impairment [6].

\section{The conclusions:}

- $\quad$ Provision of a network of continuous accessible walkways and ramps connecting the various facilities for the general public, people with baby strollers, people with disabilities and the elderly to go anywhere.

- Easy connection from public transportation and provision of way finding clues in the streets would enhance access and approach to the railway station.

- A range of passive and active activities should be provided to suit individual physical ability.

\section{Recommendations:}

There are positive and negative attributes became apparent early on in the consultation process that the individual research findings tended to cluster around seven main themes. The themes are as follows [7]:

- $\quad$ Setting up of a consultative committee with disabled representatives

- Improvement made on the Central Registry System

- Promotion of Community Education

- Improvement in mobility

- Provision of accessible public transport

- Economic Implications

- Maintenance, management, durability and sustainability

\section{References}

[1] Michailakis, D. 1997. Government implementation of the standard rules as seen by member organizations of the World Federation of the Deaf. Egypt: Association of the Deaf.

[2] CEUD, 2013. National Disability Authority (NDA). [Online] Available at: http://www.universaldesign.ie/terminals

[3] Preiser, W. and Ostroff, E. 2001. Universal design handbook. New York: McGraw-Hill.

[4] Holten, S., 2003. Planning A Barrier-Free City of Toronto. s.l.:s.n.

[5] Botelle, M. Z. a. B., 2012. Dubai Metro: building the world's longest driverless metro. ICE “Institute of Civil Engineering”.

[6] Author analysis.

[7] Grey, T. and Siddall, E. (2011). Shared Space, Shared Surfaces and Home Zones from a Universal Design Approach for the Urban Environment in Ireland (1st ed.). Ireland. 